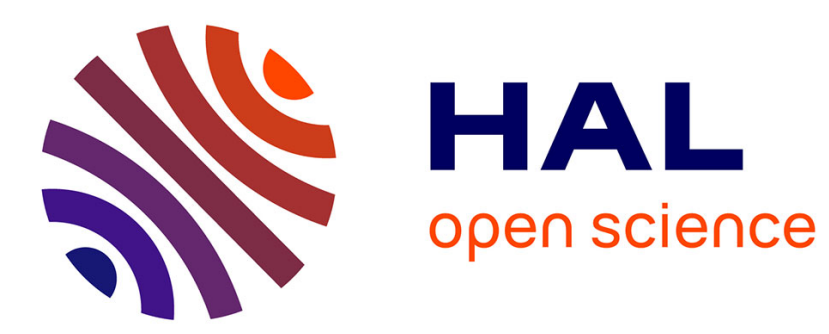

\title{
Oxidant selection to treat an aged PAH contaminated soil by in situ chemical oxidation.
}

Julien Lemaire, Michel Buès, Tanina Kabeche, Khalil Hanna, Marie-Odile

Simonnot

\section{- To cite this version:}

Julien Lemaire, Michel Buès, Tanina Kabeche, Khalil Hanna, Marie-Odile Simonnot. Oxidant selection to treat an aged PAH contaminated soil by in situ chemical oxidation.. Journal of Environmental Chemical Engineering, 2013, 1 (4), pp.1261-1268. 10.1016/j.jece.2013.09.018 . hal-00916658

\section{HAL Id: hal-00916658 \\ https://hal.science/hal-00916658}

Submitted on 10 Dec 2013

HAL is a multi-disciplinary open access archive for the deposit and dissemination of scientific research documents, whether they are published or not. The documents may come from teaching and research institutions in France or abroad, or from public or private research centers.
L'archive ouverte pluridisciplinaire HAL, est destinée au dépôt et à la diffusion de documents scientifiques de niveau recherche, publiés ou non, émanant des établissements d'enseignement et de recherche français ou étrangers, des laboratoires publics ou privés. 


\title{
Oxidant selection to treat an aged PAH contaminated soil by in situ chemical
}

\section{oxidation}

Julien LEMAIREa,b,c, Michel BUÈSc, Tanina KABECHE, ${ }^{\mathrm{a}, \mathrm{b}}$, Khalil HANNA ${ }^{\mathrm{d}, \mathrm{e}}$, Marie-Odile SIMONNOTa, ${ }^{\mathrm{a}}{ }^{*}$

a Université de Lorraine, Laboratoire Réactions et Génie des Procédés, CNRS UMR 7274, 1 rue Grandville, BP 20451, 54001 Nancy Cedex, France,

${ }^{b}$ CNRS, Laboratoire Réactions et Génie des Procédés UPR3349, 1 rue Grandville, BP 20451, 54001 Nancy Cedex, France, c Université de Lorraine/CNRS/CREGU, UMR 7359 GeoRessources, rue du Doyen Marcel Roubault, TSA 7060554518 Vandouvre-lès-Nancy France

' Ecole Nationale Supérieure de Chimie de Rennes, UMR CNRS 6226,, 11 Allée de Beaulieu, CS 50837, 35708 Rennes Cedex 7, France

e Université Européenne de Bretagne, 5 Boulevard Laënnec 35000 Rennes, France

${ }^{*}$ Corresponding author: phone: $+33(0) 383175$ 260; fax: $+33(0) 383322$ 975; e-mail: MarieOdile.Simonnot@univ-lorraine.fr

\begin{abstract}
This work is a part of the OXYSOL project aiming at the conception of a global treatment pathway including In Situ Chemical Oxidation to clean up soils of former metallurgical sites. It deals with the selection of the most adapted oxidants. Batch experiments were performed with aged contaminated soil samples of a former steel-making plant to degrade the 16 US
\end{abstract}


EPA PAHs. In this research, hydrogen peroxide, modified Fenton's reaction, potassium permanganate, sodium percarbonate and sodium persulfate were compared at high and moderate doses. Hydrogen peroxide, modified Fenton's reagent, percarbonate and activated persulfate led to a maximum degradation ratio of $45 \%$. A higher ratio $(70 \%)$ was obtained with a high dose of permanganate. Except for permanganate, increasing oxidant dose did not improve degradation rates, especially with radical-based oxidative systems probably due to radical scavenging. Oxidant doses had an effect on $\mathrm{pH}$ that drastically increased or dropped in some cases, which was a drawback. Permanganate efficacy was mainly assigned to its persistence. In all cases, the low availability of PAHs, partly sequestrated in the aged soil, was identified as the most limiting factor for degradation performance. Oxidants were ranked according to their efficiency for PAH oxidation in soils. Efficiency was not correlated to the doses.

Key-words: in situ chemical oxidation; PAHs; aged contaminated soil; batch experiments; availability

\section{Introduction}

Former steel-making factories, manufactured gas plants and wood treatment facilities has given birth to huge brownfields contaminated by polycyclic aromatic hydrocarbons (PAHs) $[1,2]$. PAH content may range from a few thousands to a few tens of thousands ppm. Around 130 PAHs have been identified but the most studied are the 16 PAHs listed by the US Environmental Protection Agency (US EPA) as priority contaminants. Some of them are known to be toxic, carcinogenic and mutagenic [3]. PAHs are neutral and hydrophobic 
molecules, rather thermally stable, and slowly degraded by microorganisms; they are low volatile, low soluble in water and strongly sorbed onto soil organic matter (SOM) [2]. The initial reversible sorption is followed by a slow diffusion into the matrix, known as aging process. PAHs that have been present for years in a soil matrix are very little extractable and bioavailable [4-6].

For these reasons, PAH remediation is a complex task [3]. Generally, the most contaminated soil fractions are treated by thermal desorption after excavation while for lower contamination levels, biological treatments are more appropriate and cheaper [7]. Biological treatments are effective for low-molecular weight PAHs but degradation is limited by PAH low availability $[5,6,8]$. In this context, in situ chemical oxidation (ISCO) is a promising alternative, which can be very efficient in a relatively short time period. ISCO aims at the degradation of the target contaminants after their reaction with an oxidant injected into the groundwater or soil [9-12].

The conventional oxidants are ozone, permanganate, Fenton's reagent, percarbonate and activated persulfate. Permanganate, used as sodium or potassium permanganate has been extensively investigated and applied $[9,10,13]$. With a standard oxidation potential of $1.7 \mathrm{~V}$, it is considered as a strong oxidant able to break carbon-carbon double bonds, aldehyde and hydroxyl groups, but not benzene rings. Then it was believed that permanganate was not suitable for PAH oxidation, but many contributions have shown its effectiveness for these pollutants [14-18]. Permanganate has the advantage to be very persistent in soils, but it can be consumed by many side reactions (e.g. SOM oxidation) leading to a high natural soil demand. Recently, it has become available in the form of slow-release paraffin- $\mathrm{KMnO}_{4}$ candles allowing a progressive distribution and able to degrade PAHs in groundwater [19]. Another oxidant that has been widely studied is hydroxyl radical, which is a very strong 
oxidant (standard oxidation potential $2.8 \mathrm{~V}$ ) [9-12, 20-23]. It is generated by the decomposition of hydrogen peroxide in the presence of ferrous ions. This reaction is known as "Fenton reaction" when run at acidic pH (ca 3) and "Modified Fenton Reaction" (MFR) when run at near neutral or natural soil $\mathrm{pH}$. Chelating agents are often used to maintain iron in solution, preventing iron precipitation (citric acid, EDTA, sodium pyrophosphate) [24]; sodium pyrophosphate was found the most effective for PAH treatment. Instead of using iron solutions, some authors have shown the effectiveness of iron oxides for heterogeneous catalysis: goethite, hematite, ferrihydrite or magnetite $[25,26]$. In some cases, no iron is added and activation is done by endogenous iron [12], the reaction is called "Fenton-like reaction". Hydrogen peroxide is hazardous since its decomposition is highly exothermic, then slow-release compounds have been developed, namely sodium percarbonate [27, 28]. It has seldom been used for PAH remediation and was less effective than catalysed hydrogen peroxide [29]. More recently, sulfate radical, a strong oxidant (standard oxidation potential 2.6 V) obtained by activation of sodium persulfate has been tested for pollutant removal [911, 15, 30-32]. Activation can be performed by several methods: thermal photochemical or chemical using dissolved iron or solid iron (e.g. magnetite), in alkaline conditions or with hydrogen peroxide [15, 30, 33-35].

The choice of an oxidant for a given remediation situation is governed by several factors. The soil composition (SOM nature and content), the texture and porosity strongly affect PAH availability. $\mathrm{pH}$ is also of importance since a low $\mathrm{pH}$ is preferred for Fenton's reaction while persulfate treatment is favoured at a high $\mathrm{pH}$. Operational conditions (temperature, injection procedure, reaction time) also have a significant influence. In some cases, treatment effectiveness increases with oxidant dosage but when radicals are involved, reaction may be stopped by radical scavenging and so a high oxidant dose can cause negative effects. For 
these reasons, a bench scale study is required for each remediation situation with the aim to choose the best operational conditions and predict the expected $\mathrm{PAH}$ degradation rate. However, in many situations of aged soil remediation, a very high PAH removal rate is not directly attained with oxidation and a post-treatment by bioremediation is performed to achieve clean-up objectives [8, 36-38].

The present work was the first step of the OXYSOL project (http://www.oxysol-anr.org). OXYSOL aimed at combining ISCO, bioremediation and soil restoration [39] for the remediation of contaminated topsoil of a former steel-making factory contaminated by PAHs and metals. The objective of the present contribution was to compare the effects of oxidants at the bench scale to select the best candidates to degrade the 16 US EPA PAHs with doses of oxidants as low as possible, in order to minimize treatment cost and environmental impacts. Were used (i) persistent oxidants obeying redox reactions: potassium permanganate and sodium persulfate and (ii) radical-based oxidant systems: hydrogen peroxide, Fenton's reagents with different additives, sodium percarbonate and activated persulfate. For Fenton's system, we tested citric acid to avoid iron hydroxide precipitation and a cyclodextrin to enhance PAH desorption/availability. The experiments were started with relatively high amounts of oxidants to test the limits of the reactions and then the doses were lowered.

\section{Materials and Methods}

\subsection{Chemicals}


A standard solution of the 16 USA EPA PAHs standard (1 mg L-1 each) and sulfuric acid (96\%) were supplied by Sigma-Aldrich, sodium percarbonate by Solvay Chemicals, sodium persulfate (> 99\%) by Acros Organics, ortho-phosphoric acid (85\%) by Merck, potassium permanganate (> 99\%) by Fluka Chemika, citric acid (>99\% ) by Prolabo, hydroxypropylbeta-cyclodextrin by Molekula, hydrogen peroxide (50\%), ferrous sulfate heptahydrate Rectapur and sodium carbonate Normapur by VWR.

\subsection{Soil sample}

The sample was a sandy loam soil collected at a former steel-manufacturing site (NeuvesMaisons, Northeastern France) [33, 40-44]. This soil was previously thoroughly characterised: the composition of all the size fractions and the distribution of PAHs and metals among these fractions had been determined; morphologies had been observed by SEM [41, 44]. It had been shown that 69 wt \% of the material was formed of particles larger than $2 \mathrm{~mm}$, composed of various materials formed in blast-furnace. In the present study, a $20 \mathrm{~kg}$ sample was air-dried, and sieved to $2 \mathrm{~mm}$. Soil analyses were performed by the Laboratory of Soil Analyses (Arras, France): particle size distribution, $\mathrm{pH}$, total carbonate, total organic carbon. Soil $\mathrm{pH}$ was measured in water suspension at the ratio $1 / 5(\mathrm{v} / \mathrm{v})$ (NF ISO 10390). Total carbonate (NF ISO 10693) was determined by measurement of the emitted volume of $\mathrm{CO}_{2}$ during sample acidification with $\mathrm{HCl}$. Total C (NF ISO 10694) was determined by dry combustion and quantification of the emitted volume of $\mathrm{CO}_{2}$. Organic carbon was calculated from the difference between total carbon and total carbonate. Trace elements were measured by ICP-OES (Cr, Cu, Ni and $\mathrm{Zn})$ and by ICP-MS (Pb) after lithium metaborate attack and acid digestion. PAHs were analysed as described in section 2.4. 
The sieved sample was composed of $62.9 \mathrm{wt} \%$ sand, $24.1 \mathrm{wt} \%$ silt and $13.0 \mathrm{wt} \%$ clay. It contained $71.5 \mathrm{~g} \mathrm{~kg}^{-1}$ organic carbon, $1.55 \mathrm{~g} \mathrm{~kg}^{-1}$ of the 16 US EPA PAHs and heavy metals: Zn (2.6 $\left.\mathrm{g} \mathrm{kg}^{-1}\right), \mathrm{Pb}\left(684 \mathrm{mg} \mathrm{kg}^{-1}\right), \mathrm{Cr}\left(325 \mathrm{mg} \mathrm{kg}^{-1}\right), \mathrm{Ni}\left(260 \mathrm{mg} \mathrm{kg}^{-1}\right)$, and $\mathrm{Cu}\left(110 \mathrm{mg} \mathrm{kg}^{-1}\right)$. The distribution of the 16 PAHs was (in $\mathrm{mg} \mathrm{kg}^{-1}$ ): naphthalene 30.0, acenaphtylene 1.7, acenaphtene 62.0, fluorene 57.0, phenanthrene 170.0, anthracene 63.0, fluoranthene 250.0, pyrene 200.0, chrysene 110.0, benzo(a)anthracene 130.0, benzo(b)fluoranthene 120.0, benzo(k)fluoranthene 68.0, benzo(a)pyrene 120.0, dibenzo(a,h)anthracene 13.0, benzo(g,h,i)perylene 71.0, indeno(1,2,3-cd)pyrene 85.0. The calcium carbonate content was 35 $\mathrm{g} \mathrm{kg}^{-1}$ and $\mathrm{pH}$ in water 7.4.

\subsection{Batch experiment design}

\subsubsection{Stoichiometric molar ratio}

To compare the results, oxidant doses were expressed in terms of stoichiometric molar demand (SOD) calculated from the stoichiometric molar ratio (SMR) previously defined [16, $20,28,43]$. SMR is the number of moles of an oxidant required to degrade one mole of a target component into $\mathrm{CO}_{2}$ and $\mathrm{H}_{2} \mathrm{O}$. Stoichiometric coefficients were obtained by listing the reactions between each oxidant and each PAH and SMR was calculated as the weighted average of these coefficients for the soil sample.

Then the stoichiometric oxidant demand yields:

$$
S O D=M_{o x} S M R[P A H]
$$


where SOD is expressed in $\mathrm{g}\left(\mathrm{kg}_{\mathrm{dry}} \text { soil }\right)^{-1}, \mathrm{Mox}$ is the molar mass of the oxidant $\left(\mathrm{g} \mathrm{mol}^{-1}\right), \mathrm{SMR}$ the stoichiometric molar ratio (-) and [PAH] the 16 US EPA PAHs content in the soil sample $\left(\mathrm{mol}(\mathrm{kg} \text { dry soil })^{-1}\right)$. Details and examples are given in a previous reference [43].

With this soil sample, for respectively hydrogen peroxide, sodium percarbonate, sodium persulfate and sodium permanganate, SMR was equal to $38.5,12.8,38.5$ and 25.6 and SOD to 9.7, 29.8, 67.8 and $30.0 \mathrm{~g}\left(\mathrm{~kg}_{\text {dry soil }}\right)^{-1}$. SOD was calculated to compare oxidant efficiency at equivalent doses but not to estimate required oxidant amount to achieve PAHs degradation. Indeed, this calculation method does not take into account concurrent SOM degradation.

\subsubsection{PAH oxidation with high doses of oxidants}

Three doses of oxidants were used corresponding to 7.5-, 15- and 30-fold SMR (Table 1) and a control experiment without oxidant was run as well. For MFR, was chosen the conventional molar ratio $\left[\mathrm{H}_{2} \mathrm{O}_{2}\right]:\left[\mathrm{FeSO}_{4}\right]=10: 1$ [20] (Table 1); $\mathrm{pH}$ was kept at its natural value. They were also run without iron sulfate or with citric acid or with hydroxy-propylbeta-cyclodextrin at the molar ratio $\left[\mathrm{H}_{2} \mathrm{O}_{2}\right]$ : $\left[\mathrm{FeSO}_{4}\right]$ :[cyclodextrin $]=20: 2: 1$ (Table 1).

\section{Please insert Table 1}

Sodium persulfate was used without and with activation by $50 \%$ hydrogen peroxide at the molar ratio $\left[\mathrm{H}_{2} \mathrm{O}_{2}\right]:\left[\mathrm{Na}_{2} \mathrm{~S}_{2} \mathrm{O}_{8}\right]=5: 1[45]($ Table 1$)$.

For all experiments, $10 \mathrm{~g}$ (dry mass) of soil samples were placed in $250 \mathrm{~mL}$ flasks, $20 \mathrm{~mL}$ of ultra-pure water were added followed by the required quantities of oxidants. Flasks were covered with an aluminum foil to avoid photochemical degradation and stirred at $250 \mathrm{rpm}$ at 
$20{ }^{\circ} \mathrm{C}$. After $4 \mathrm{~d}, \mathrm{pH}$ was measured in the slurries; the samples were filtered with a cellulose filter, dried for $2 \mathrm{~d}$ at $20^{\circ} \mathrm{C}$ and weighed. The residual water content was determined by weighing a sample before and after $24 \mathrm{~h}$ drying at $105{ }^{\circ} \mathrm{C}$ in an oven. Then $10 \mathrm{~g}$ of each sample were ground with a laboratory ball mill to improve homogeneity before analysis. Residual concentrations of permanganate and persulfate in the liquid phase were measured.

\subsubsection{PAH oxidation with medium doses}

Oxidation was run with $60 \mathrm{~g}$ soil samples in $250 \mathrm{~mL}$ flasks with $120 \mathrm{~mL}$ ultra-pure water. For Fenton's reagents and activated persulfate were used oxidant amounts corresponding to 1-, 2-, 4-, 8- and 16-fold SMR (Table 1). The ratio $\left[\mathrm{H}_{2} \mathrm{O}_{2}\right]:\left[\mathrm{FeSO}_{4}\right]$ was kept at 10:1 as $\left[\mathrm{H}_{2} \mathrm{O}_{2}\right]:\left[\mathrm{Na}_{2} \mathrm{~S}_{2} \mathrm{O}_{8}\right]$ was increased up to $10: 1$. Reactants were alternatively and progressively introduced to improve their efficiency (Table 1). With activated persulfate, $70 \mathrm{mg}$ sodium persulfate were added each $5 \mathrm{~min}$, followed by $140 \mu \mathrm{L} 50 \%$ hydrogen peroxide $1 \mathrm{~min}$ after, until the required oxidant amount was reached. MFR was performed in the same way, by adding each time $80 \mathrm{mg}$ ferrous sulfate heptahydrate, followed by $160 \mu \mathrm{L} 50 \%$ hydrogen peroxide.

The same experiments were run with medium amounts of permanganate and persulfate corresponding to 0.75-, 1.5- and 3-fold SMR (Table 1). After $9 \mathrm{~h}, \mathrm{pH}$ was measured in the slurries before being freeze-dried and ground with a laboratory ball mill.

\subsection{Analytical methods}




\subsubsection{Analyses of the 16 PAHs in the soil sample}

PAHs were extracted by ASE (Accelerated Solvent Extraction) from $1 \mathrm{~g}$ soil sample, previously dried and ground, with acetone/dichloromethane (50:50 v/v) at 120 bars and 100 ${ }^{\circ} \mathrm{C}$. The solvent was evaporated and the residue diluted in $10 \mathrm{~mL}$ acetonitrile. HPLC analyses were run with a Shimadzu LC-10AVP equipped with a photodiode array detector, using a Prosphere column (Alltech, $250 \mathrm{~mm} \times 46 \mathrm{~mm}$, particle size $5 \mu \mathrm{m}, 300 \AA$ ). The mobile phase was ultra-pure water/acetonitrile with a gradient between 85:15 and 95:5 v/v (flow rate $=0.4$ $\left.\mathrm{mL} \min ^{-1}\right)$. External calibrations were done with standard solutions of 16 US EPA PAHs in acetonitrile in the $1-100 \mathrm{mg} \mathrm{L}^{-1}$ range.

Analytic replicates and statistic tests were performed because of the heterogeneity of soil samples. Fischer's tests proved that standard deviation could be considered as a constant $\left(160 \mathrm{mg} \mathrm{kg}^{-1}\right)$. Then, normal z-tests were run to compare degradation ratio to the reference value of 16 PAHs concentration estimated from 16 PAHs analysis (5 before treatment and 10 after control treatment with water). $95 \%$ confidence intervals were drawn on figures to show which differences were significant (two mean values should not belong to the same confidence interval).

\subsubsection{Residual oxidant analysis}

Residual permanganate was titrated by hydrogen peroxide and vice-versa [46]. Persulfate sample was acidified with sulfuric and phosphoric acids and Fe(II) added in excess was titrated by permanganate [46]. 


\subsubsection{TOC analysis}

Total Organic Carbon in the liquid phase was analysed by using a Shimadzu ${ }^{\circledR}$ TOC-V $\mathrm{CSH}$ analyzer.

\section{Results and discussion}

\subsection{PAH oxidation with hydrogen peroxide and Fenton's reagents}

PAH residual concentrations and degradation ratios at high and moderate oxidant doses are plotted in Fig. 1a and 2. Degradation ratios were calculated as:

$$
\text { Degradation ratio }(\%)=\left[1-\frac{(P A H)_{\text {final }}}{(P A H)_{\text {initial }}}\right] \times 100
$$

where $(\mathrm{PAH})_{\text {final }}$ and $(\mathrm{PAH})_{\text {initial }}$ were the concentrations of the $16 \mathrm{PAHs}$ respectively at the end and before the reaction $\left(\mathrm{g} \mathrm{kg}_{\mathrm{dry}} \mathrm{soil}^{-1}\right)$.

At high dosage, degradation ratios were between 0 and $45 \%$ with $95 \%$ confidence interval of $\pm 15 \%$ with hydrogen peroxide, Fenton's reagent alone and with citric acid or cyclodextrin (Fig. 1a). The best result was obtained with hydrogen peroxide at 15-fold SMR. At 30-fold SMR, degradation was not significantly higher ( $\mathrm{p}$-value $<5 \%$ ). The addition of Fe(II) led to respectively 30, 0 and 20\% degradation at 7.5, 15, 30-fold SMR. Addition of citric acid or cyclodextrin had no effect at the lowest dose but slightly increased degradation at 15 and 30-fold SMR compared to modified Fenton's reaction (p-value near 5\%). At low dosage with MFR, with gradual reactant addition, degradation ratios were respectively 0 and $15 \%$ at 1- 4-fold SMR, 95\% confidence interval of $\pm 7 \%$ (Fig. 2). Experiments repeated with MFR at 8 
and 16-fold SMR with gradual reactant addition (not shown) were comparable to the results shown in Fig. 1 (p-values $<5 \%$ ).

\section{Please insert Fig. 1}

Please insert Fig. 2

A striking feature in Fig. 1 and 2 is the relatively low degradation ratio (maximum value: $45 \%)$ obtained whatever the reactants and dosage, while values up to $98 \%$ have been reported $[15,17,23,47-49]$. PAH oxidation ratios are governed by a number of parameters, regarding soil properties, pollutant status and reaction conditions $[9,10,23]$. Soil texture and porosity may have a significant effect $[23,47]$ as well as the level and composition of organic matter $[17,23]$. Natural organic matter (fulvic and humic acids) and anthropogenic organic matter (e.g. coal tar) strongly sorb PAHs, sorption increases with organic matter hydrophobicity, which may hinder contact between PAHs and oxidant and limit the reaction extent. Besides, organic matter is a competitor for oxidation reaction and a significant part of the oxidant may be consumed by organic matter [17]. In the present case, the high content of organic matter $\left(71.5 \mathrm{~g} \mathrm{~kg}^{-1}\right)$, mainly of anthropogenic origin, may have consumed a large part of the oxidant. This figure is rather common however, as the soil used in this work was in in the same range as other industrial soils [17].

Concerning pollutant status, it has been shown that PAH initial concentration and $\mathrm{PAH}$ repartition between low and high molecular weight compounds also had an influence on degradation $[15,23]$. The total PAH concentration, $1.55 \mathrm{~g} \mathrm{~kg}^{-1}$, was in the same range as in other reports $[15,17,37]$ and the distribution of the 16 US EPA PAHs corresponded to the signature of former coking sites [40]. The low molecular weight PAHs (naphthalene to fluoranthene), as defined in [15], represented 41 wt \% while the heavy PAHs (pyrene to indeno (1,2,3-cd)pyrene) $59 \mathrm{wt} \%$. The heavy fraction was higher than in other studies (30 to 
50 wt \%) [15, 17, 37], which contributed to reduce the degradation rate. Another very important characteristic of PAHs in this aged soil was their very poor availability: as previously proved, PAHs could not be extracted from this soil by hydroxypropyl-betacyclodextrin [43]. This very low availability dramatically reduced the transfer of PAH from the solid matrix to the liquid phase, which is considered as a considerable obstacle for oxidation efficiency.

Comparison with literature data can be made, taking into account, however, that oxidation conditions, i.e. oxidant concentrations, oxidant:catalyst molar ratio and presence of chelating agents as well as $\mathrm{pH}$, reaction duration and temperature, were different. In our

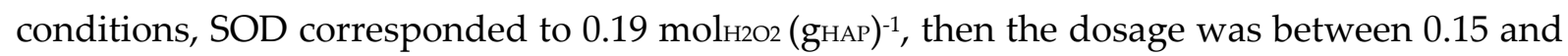
5.8 mol$_{\mathrm{H} 2 \mathrm{O} 2}\left(\mathrm{gHAP}^{-1}\right.$, which was consistent for instance with [15], in which the range was 0.59 to $2.37 \mathrm{molH}_{\mathrm{H}}\left(\mathrm{gHAP}^{-1}\right.$. In the same way, we found that the dosage should not be too low, but from a certain point, an increase in concentration has adverse effects, mainly of termination reactions between radicals (radical scavenging). The best degradation ratio was obtained without adding $\mathrm{Fe}(\mathrm{II})$ as soil metal content was sufficient to catalyse peroxide decomposition. Actually the addition of iron salt resulted in a rapid peroxide decomposition, with temperature increase at high dosage, leading to a too fast consumption of hydroxyl radical. Therefore, iron concentration should be kept as low as possible, to avoid rapid decomposition and formation of iron sludge $[23,37]$. Chelating agent may enhance iron stabilization and avoid iron precipitation $[15,24]$. Here, the degradation ratio did not increase significantly with the addition of citric acid (Fig. 1a). As expected, the effect of citric acid was higher at higher dosage (30-fold SMR). Also, the use of cyclodextrin to enhance PAH desorption was not very effective (Fig. 1a). The solutions have turned brownish, showing that organic matter has been extracted, which consumed part of the radicals. The 
high carbonate content of this soil sample, along with a high soil $\mathrm{pH}$, had a negative impact on oxidation reactions. More favorable conditions would request low $\mathrm{pH}$ values as in conventional Fenton's reaction. MFR can be run at the vicinity of neutrality as with our soil, however the rather high carbonate content leads to hydrogenocarbonate and carbonate ions transfer to the liquid phase, which also increases hydroxyl radical scavenging $[9,10,28]$.

To summarise, this aged soil sample was difficult to treat with Fenton's reagent for several reasons but mainly because of the very poor PAH availability. The highest PAH oxidation ratio was $45 \%$. A too high oxidant dosage hindered reactions by radical scavenging. Also hydrogen peroxide decomposition could occur without iron salt addition. However, co-reactants should be gradually added. Finally, the use of cyclodextrin and/or iron chelating agents did not improve the oxidation process, they should be avoided because of additional cost and possible toxicity.

\subsection{PAH oxidation with sodium percarbonate and carbonate}

The results of PAH oxidation with percarbonate and carbonate are presented in Fig. 1b with $95 \%$ confidence interval of $\pm 10 \%$. With percarbonate, slowly delivering hydrogen peroxide, activated by iron (II), PAH degradation roughly showed the same trend as with MFR. It was lower, however, $10 \%$ at 7.5 -fold SMR, $0 \%$ at $15-$ and $20 \%$ at 30 . No heat release occurred. The supernatant turned brownish, a sign of SOM extraction. Then sodium carbonate was tested for comparison. The same color was observed and the degradation ratios were in the same range: respectively 15,15 and $0 \%$ at 7.5-, 15- and 30-fold SMR. In both cases, high pHs were attained, up to 10.5 at 15 and 30-fold SMR with percarbonate (Fig. 3). Analysis of PAHs and TOC in the supernatant revealed an alkaline extraction of organic 
matter: extracted TOC increased from 1,700 to $9,800 \mathrm{mg}^{\mathrm{kg}_{\mathrm{dry}}}$ soil $^{-1}$ with increasing percarbonate concentrations and from 1,100 to $2,400 \mathrm{mg} \mathrm{kg}$ dry soil ${ }^{-1}$ with increasing carbonate concentrations (supplementary materials). TOC extraction was systematically higher with percarbonate than with carbonate, as was $\mathrm{pH}$. The same was observed with extracted PAHs that increased from 0 to respectively 0.730 and $0.260 \mathrm{mg} \mathrm{kg}_{\text {dry }}$ soil $^{-1}$ when increasing percarbonate and carbonate concentrations.

Hence, organic matter and PAHs were extracted from soil by carbonate and percarbonate. But this washing effect was not the unique process, since the amounts of PAHs removed from soil were higher than the amount of PAHs detected in solution.

\section{Please insert Fig. 3}

In the context of the OXYSOL project was decided to avoid the use of percarbonate because of the low degradation rates, the extraction of SOM and the $\mathrm{pH}$ increase, which can be a serious drawback for post-treatment such as bioremediation.

\subsection{PAH oxidation with potassium permanganate}

Permanganate enabled us to reach the highest degradation rates: 40 to $50 \%$ at respectively 7.5 and 15 -fold SMR to $70 \%$ at 30 -fold SMR (Fig. 1b). The same was observed at low dosage: $35 \%$ at 3-fold SMR (Fig. 2). An important result was that a significant positive correlation between degradation ratio and permanganate dosage, from a Pearson's correlation coefficient r-test.

However, permanganate is not the best oxidant for PAHs, even if positive results were already reported [13-18]. Additionally to its reactivity, its performances were assigned to its high persistence [9-11]. It was still present in the solution after $4 \mathrm{~d}$ (Fig. 4) and 90-95\% has 
been consumed in the reaction period. Its efficiency can also be due to the redox mechanism that may be more adapted to treat our soil than radical mechanism. Permanganate may also be more specific to PAHs than radicals that are consumed by organic matter $[12,18]$. Besides, its lower sensitivity to $\mathrm{pH}$ conditions is an advantage.

Then for the first step of the OXYSOL procedure, permanganate appears as a very promising oxidant. However, the formation of manganese dioxide may cause problems for the post-treatment including site vegetation, since manganese dioxide in excess prevents plant germination and growth [17].

Please insert Fig. 4

\subsection{PAH oxidation with sodium persulfate and activated sodium persulfate}

At high dosage, degradation ratios with persulfate were in the range 0 to $25 \%$ and not directly correlated to the oxidant dose (Fig. 1a). Persulfate is persistent and $30-45 \%$ were still present in solution after $4 \mathrm{~d}$ (Fig. 4). But PAH degradation was always significantly lower than with permanganate ( $\mathrm{p}$-value $<5 \%$ ). Also a sharp decrease in $\mathrm{pH}$ was recorded with increasing persulfate additions, reaching ca. 2 with a 15-fold SMR (Fig. 3). This $\mathrm{pH}$ drop could be a major limitation since persulfate is known to be more efficient in alkaline conditions $[35,45]$.

Degradation ratio was significantly higher with persulfate activated by $\mathrm{H}_{2} \mathrm{O}_{2}$ than with persulfate at 7.5-fold SMR (25\%). But it was lower at 30 -fold SMR $(10 \%)$, as a result of the formation of sulphate and possibly of hydroxyl radicals which increased PAH oxidation except at high rates because of radical scavenging. Comparable results have been obtained [15] with a limit of $30 \%$ degradation. Oxidant was still detected after $4 \mathrm{~d}$ (Fig. 4), but the 
consumption rate was significantly higher than for persulfate ( $\mathrm{p}$-value $<5 \%$ ). Radicals were rapidly consumed and unactivated persulfate in excess remained in the solution. As previously, $\mathrm{pH}$ decreased with the dose increase but not so drastically, it dropped to 4.3 instead of 2.

In the same way as for MFR, the limited degradation was due to the poor PAH availability in this soil. These results are consistent with the findings obtained for the same soil using the magnetite-activated persulfate system [33]. A limit of 50\% degradation was recorded, which was a little higher than in our case but of the same order. A possible method to increase the efficacy of activated persulfate would be to use other activation methods. Recently, thermal activation has proved to be more efficient for PAH degradation [35], a result consistent with observed positive effect of temperature increase on oxidation rates [40]. But soil heating is not technically and economically feasible at large scale.

To summarize, the use of persulfate activated by hydrogen peroxide is also of interest in the OXYSOL procedure, because of its efficacy combined to the persistence of persulfate. Again a limited degradation ratio was recorded because of PAH low availability, and oxidation must be combined with post-treatment. Also, persulfate have been proved to affect biological parameters, e.g. inhibition of the soil microbial community [38] and low dosage should be chosen. This is also important to avoid the dissemination of sulfate in soil and groundwater.

\section{Conclusion}

The remediation of PAH aged contaminated soils using chemical oxidation technology remains a big challenge. PAHs are persistent and poorly available contaminants strongly 
bound to the soil matrix (organic and mineral constituents). Moreover, high content of soil organic matter can consume significant amounts of oxidants. This contribution focused on the method to select an oxidant at the bench scale to ensure further feasible remediation at the field scale. To keep in feasible conditions, the amounts of oxidant must remain low to moderate. Oxidation efficacy depends on many parameters including soil properties, pollutant nature and localisation and operating conditions. Then each situation has to be thoroughly investigated at the bench scale. The main conclusions and recommendations that can be drawn from this work concern the choice of nature/dose of employed oxidant, and the effect of pollutant availability. Permanganate, hydrogen peroxide, modified Fenton's reaction and activated persulfate have proved their efficacy, while sodium percarbonate was not so relevant. We showed that, except for permanganate, increasing of the oxidant dose had positive effects till an optimum value, afterward opposite effects occur. With permanganate, PAH degradation ratio was positively correlated to oxidant dosage; however the main drawback of permanganate is the formation of manganese dioxide that can strongly affect soil permeability and possibility of further vegetation [17]. In comparison, $\mathrm{O}_{2}$ release and faster reaction with Fenton's reagent and activated persulfate are more favorable to bioremediation and soil construction [38].

The main conclusion concern the influence of pollutant availability in the case of persistent organic pollutants (PAHs, PCBs etc.) strongly sorbed on aged soils. This work has shown how limiting it was. Availability should be thoroughly studied before remediation decision making [50]. But pollutant availability remains difficult to evaluate and therefore more research is still needed to develop new experimental tools and evaluation methods.

\section{Acknowledgements}


This project was supported by GISFI, research group on soil pollution (http://www.gisfi.fr), financed by PRECODD Program of the French national research agency "ANR" and by "Région Lorraine". The authors are very grateful. They also thank their colleagues involved in OXYSOL, particularly Pr J.L. Morel, Dr P. Faure, Dr A. Saada, Mr R. Jacquet, Dr C. Leyval, Pr C. Schwartz, Dr F. Laurent, Dr S. Guimont, Dr J.C. Renat and Mr P. Charbonnier. They thank Mr S. Pontvianne for his technical help.

\section{References}

[1] W. Wilcke, Polycyclic aromatic hydrocarbons (PAHs) in soil - A review, J. Plant Nutr. Soil Sc., 163 (2000) 229-248.

[2] R.G. Harvey, Polycyclic Aromatic Hydrocarbons, Wiley-VCH Publishers, 1997.

[3] B. Mahanty, K. Pakshirajan, V.V. Dasu, Understanding the complexity and strategic evolution in PAH remediation research, Crit. Rev. Env. Sci. Tech., 41 (2011) 16971746.

[4] L. Luo, S. Lin, H.L. Huang, S.Z. Zhang, Relationships between aging of PAHs and soil properties, Environ. Poll., 170 (2012) 177-182.

[5] P.B. Hatzinger, M. Alexander, Effect of aging of chemicals in soil on their biodegradability and extractability, Environ. Sci. Technol., 29 (1995) 537-545.

[6] N. Chung, M. Alexander, Differences in sequestration and bioavailability of organic compounds aged in dissimilar soils, Environ. Sci. Technol., 32 (1998) 855-860.

[7] H.D. Sharma, K.R. Reddy, Geoenvironmental Engineering: Site Remediation, Waste Containment and Emerging Waste Management Technologies, John Wiley \& Sons, Inc., Hoboken, New Jersey, 2004.

[8] P. Haapea, T. Tuhkanen, Integrated treatment of PAH contaminated soil by soil washing, ozonation and biological treatment, J. Hazard. Mater., 136 (2006) 244-250. 
[9] ITRC, Technical and Regulatory Guidance for In Situ Chemical Oxidation of Contaminated Soil and Groundwater, $2^{\text {nd }}$ ed. ISCO-2. Washington D.C.: Interstate Technology \& Regulatory Council, In Situ Chemical Oxidation team, 2005. Available on the internet at http://www.itrcweb.org.

[10] S.G. Huling, B.E. Pivetz, In-Situ Chemical Oxidation - US EPA Engineering issue, EPA/600/R-06/072, Office of Research and Development National Risk Management Research Laboratory, Cincinnati, 2006.

[11] R.L. Siegrist, M. Crimi, T.J. Simpkin, In Situ Chemical Oxidation for groundwater remediation, Springer, 2011.

[12] F.J. Rivas, Polycyclic aromatic hydrocarbons sorbed on soils: A short review of chemical oxidation based treatments, J. Hazard. Mater., 138 (2006) 234-251.

[13] G.S. Brown, L.L. Barton, B.M. Thomson, Permanganate oxidation of sorbed polycyclic aromatic hydrocarbons, Waste Manage., 23 (2003) 737-740.

[14] S.P. Forsey, N.R. Thomson, J.F. Barker, Oxidation kinetics of polycyclic aromatic hydrocarbons by permanganate, Chemosphere, 79 (2010) 628-636.

[15] E. Ferrarese, G. Andreottola, I.A. Oprea, Remediation of PAH-contaminated sediments by chemical oxidation, J. Hazard. Mater., 152 (2008) 128-139.

[16] P.T. De Souza e Silva, V.L. Da Silva, B.d.B. Neto, M.-O. Simonnot, Potassium permanganate oxidation of phenanthrene and pyrene in contaminated soils, J. Hazard. Mater., 168 (2009) 1269-1273.

[17] C. Sirguey, P. Tereza de Souza e Silva, C. Schwartz, M.-O. Simonnot, Impact of chemical oxidation on soil quality, Chemosphere, 72 (2008) 282-289.

[18] W. Chen, L. Hou, X. Luo, L. Zhu, Effects of chemical oxidation on sorption and desorption of PAHs in typical Chinese soils, Environ. Poll., 157 (2009) 1894-1903. 
[19] L. Rauscher, C. Sakulthaew, S. Comfort, Using slow-release permanganate candles to remediate PAH-contaminated water, J. Hazard. Mater., 241 (2012) 441-449.

[20] P.T. De Souza e Silva, V.L. Da Silva, B.d.B. Neto, M.-O. Simonnot, Phenanthrene and pyrene oxidation in contaminated soils using Fenton's reagent, J. Hazard. Mater., 161 (2009) 967-973.

[21] R.J. Watts, P.C. Stanton, J. Howsawkeng, A.L. Teel, Mineralization of a sorbed polycyclic aromatic hydrocarbon in two soils using catalyzed hydrogen peroxide, Water Res., 36 (2002) 4283-4292.

[22] Venny, S. Gan, H.K. Ng, Modified Fenton oxidation of polycyclic aromatic hydrocarbon (PAH)-contaminated soils and the potential of bioremediation as post-treatment, Sci. Total Environ., 419 (2012) 240-249.

[23] Venny, S.Y. Gan, N.K. Ng, Current status and prospects of Fenton oxidation for the decontamination of persistent organic pollutants (POPs) in soils, Chemical Engineering Journal, 213 (2012) 295-317.

[24] Venny, S. Gan, H.K. Ng, Inorganic chelated modified-Fenton treatment of polycyclic aromatic hydrocarbon (PAH)-contaminated soils, Chem. Eng. J., 180 (2012) 1-8.

[25] R. Matta, K. Hanna, S. Chiron, Fenton-like oxidation of TNT using different iron minerals, Sci. Total Environ., 385 (2007) 242-251.

[26] M. Usman, P. Faure, C. Ruby, K. Hanna, Remediation of PAH-contaminated soils by magnetite catalyzed Fenton-like oxidation, Appl. Catal. B-Environ., 117-118 (2012) 1017.

[27] J. Birnstingl, B. Kelley, S. Koenigsberg, Field results with an alkaline in situ chemical oxidation process, Land Contam. \& Reclam., 14 (2006) 539-539. 
[28] J. Lemaire, V. Croze, J. Maier, M.-O. Simonnot, Is it possible to remediate a BTEX contaminated chalky aquifer by in situ chemical oxidation?, Chemosphere, 84 (2011) 1181-1187.

[29] P. Cajal-Marinosa, R.G. de la Calle, F.J. Rivas, T. Tuhkanen, Impacts of Changing Operational Parameters of In Situ Chemical Oxidation (ISCO) on Removal of Aged PAHs from Soil, J. Adv. Oxid. Technol., 15 (2012) 429-436.

[30] F. Nadim, K.-C. Huang, A. Dahmani, Remediation of soil and ground water contaminated with PAH using heat and Fe(II)-EDTA catalyzed persulfate oxidation, Water Air Soil Poll., 6 (2006) 227-232.

[31] G. Andreottola, L. Bonomo, G. de Gioannis, E. Ferrarese, A. Muntoni, A. Polettini, R. Pomi, S. Saponaro, Lab-scale feasibility tests for sediment treatment using different physico-chemical techniques, J. Soils Sediments, 10 (2009) 142-150.

[32] J. Gryzenia, D. Cassidy, D. Hampton, Production and accumulation of surfactants during the chemical oxidation of PAH in soil, Chemosphere, 77 (2009) 540-545.

[33] M. Usman, P. Faure, C. Ruby, K. Hanna, Application of magnetite-activated persulfate oxidation for the degradation of PAHs in contaminated soils, Chemosphere, 87 (2012) 234-240.

[34] D. Zhao, X.Y. Liao, X.L. Yan, Z.Y. Chong, Chemical oxidants for remediation of soils contaminated with polycyclic aromatic hydrocarbons at a coking site, Huanjing Kexue/Environmental Science, 32 (2011) 857-863.

[35] D. Zhao, X. Liao, X. Yan, S.G. Huling, T. Chai, H. Tao, Effect and mechanism of persulfate activated by different methods for PAHs removal in soil, J. Hazard. Mater., 254-255 (2013) 228-235. 
[36] M.R. Palmroth, J.H. Langwaldt, T.A. Aunola, A. Goi, J.A. Puhakka, T.A. Tuhkanen, Treatment of PAH-contaminated soil by combination of Fenton's reaction and biodegradation, J. Chem.Technol. Biot., 81 (2006) 598-607.

[37] C. Valderrama, R. Alessandri, T. Aunola, J.L. Cortina, X. Gamisans, T. Tuhkanen, Oxidation by Fenton's reagent combined with biological treatment applied to a creosotecomtaminated soil, J. Hazard. Mater., 166 (2009) 594-602.

[38] N.B. Sutton, J.T.C. Grotenhuis, A.A.M. Langenhoff, H.H.M. Rijnaarts, Efforts to improve coupled in situ chemical oxidation with bioremediation: a review of optimization strategies, J. Soils Sediments, 11 (2011) 129-140.

[39] G. Séré, C. Schwartz, S. Ouvrard, C. Sauvage, J.C. Renat, J.L. Morel, Soil construction: A step for ecological reclamation of derelict lands, J. Soils Sediments, 8 (2008) 130136.

[40] C. Biache, L. Mansuy-Huault, P. Faure, C. Munier-Lamy, C. Leyval, Effects of thermal desorption on the composition of two coking plant soils: Impact on solvent extractable organic compounds and metal bioavailability, Environ. Poll., 156 (2008) 671-677.

[41] M.F. Monserie, F. Watteau, G. Villemin, S. Ouvrard, J.L. Morel, Technosol genesis: Identification of organo-mineral associations in a young technosol derived from coking plant waste materials, J. Soils Sediments, 9 (2009) 537-546.

[42] F. Laurent, A. Cébron, C. Schwartz, C. Leyval, Oxidation of a PAH polluted soil using modified Fenton reaction in unsaturated condition affects biological and physicochemical properties, Chemosphere, 86 (2012) 659-664.

[43] J. Lemaire, F. Laurent, C. Leyval, C. Schwartz, M. Bues, M.O. Simonnot, PAH oxidation in aged and spiked soils investigated by column experiments, Chemosphere, 91 (2013) 406-414. 
[44] M.-F. Monserie, Processus d'agrégation dans un technosol : contribution des constitunts anthropiques (oxydes de fer, laitiers, HAP, ETM) à la formation des associations organo-minérales, PhD dissertation INPL, Nancy, 2009.

[45] P.A. Block, R.A. Brown, D. Robinson, Novel Activation Technologies for Sodium Persulfate In Situ Chemical Oxidation, in: Proceedings of the Fourth International Conference on the Remediation of Chlorinated and Recalcitrant Compounds, 24-27 May 2004, Monterey, CA;Columbus, OH, Battelle Press; paper 2A-05.

[46] R.U. Brumblay, Quantitative Analysis - College Outline, second ed, HarperCollins, New York, 1971.

[47] B.W. Bogan, V. Trbovic, Effect of sequestration on PAH degradability with Fenton's reagent: roles of total organic carbon, humin, and soil porosity, J. Hazard. Mater., 100 (2003) 285-300.

[48] N. Kulik, A. Goi, M. Trapido, T. Tuhkanen, Degradation of polycyclic aromatic hydrocarbons by combined chemical pre-oxidation and bioremediation in creosote contaminated soil, J. Environ. Manage., 78 (2006) 382-391.

[49] S. Jonsson, Y. Persson, S. Frankki, S. Lundstedt, B. van Bavel, P. Haglund, M. Tysklind, Comparison of Fenton's reagent and ozone oxidation of Polycyclic Aromatic Hydrocarbons in aged contaminated soils, J. Soils Sediments, 6 (2006) 208-214.

[50] A.E. Latawiec, A.L. Swindell, P. Simmons, B.J. Reid, Bringing bioavailability into contaminated land decision making: The way forward?, Crit. Rev. Environ. Sci. Technol., 41 (2011) 52-77. 


\section{FIGURE CAPTIONS}

Fig. 1 PAH residual concentration and degradation ratio obtained with high doses of (a) hydrogen peroxide, Fenton's reagents without or with citric acid or cyclodextrin (b) percarbonate, carbonate, permanganate, persulfate and activated persulfate.

Fig. 2 PAH residual concentration and degradation ratio obtained with moderate doses of Fenton's reagent, permanganate, persulfate and activated persulfate.

Fig. $3 \mathrm{pH}$ of the supernatant at the end of the reaction with high doses of percarbonate, carbonate, permanganate, persulfate and activated persulfate.

Fig. 4 Rates of consumed permanganate, persulfate and activated persulfate at the end of the reactions performed with high doses.

Fig. $5 \mathrm{pH}$ of the supernatant at the end of the reaction with moderate doses of Fenton's reagent, permanganate, persulfate and activated persulfate. 


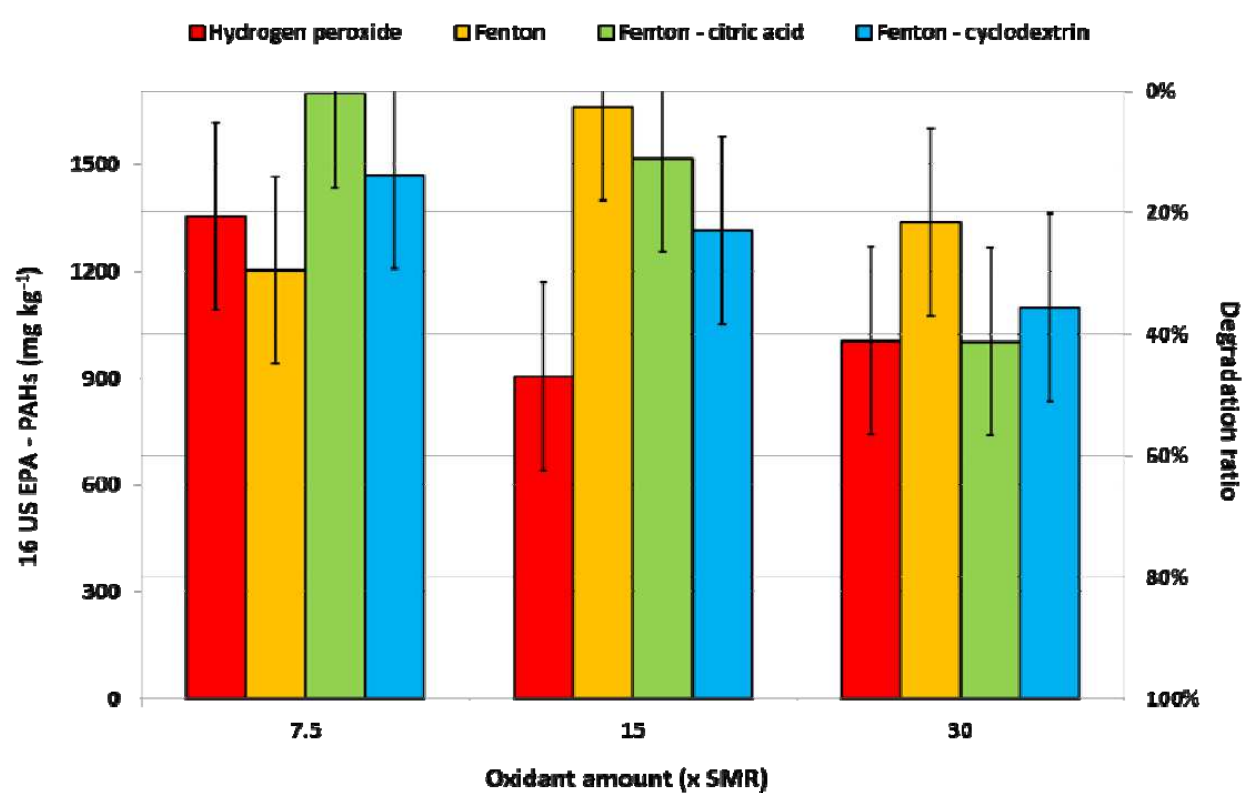

Fig. 1a

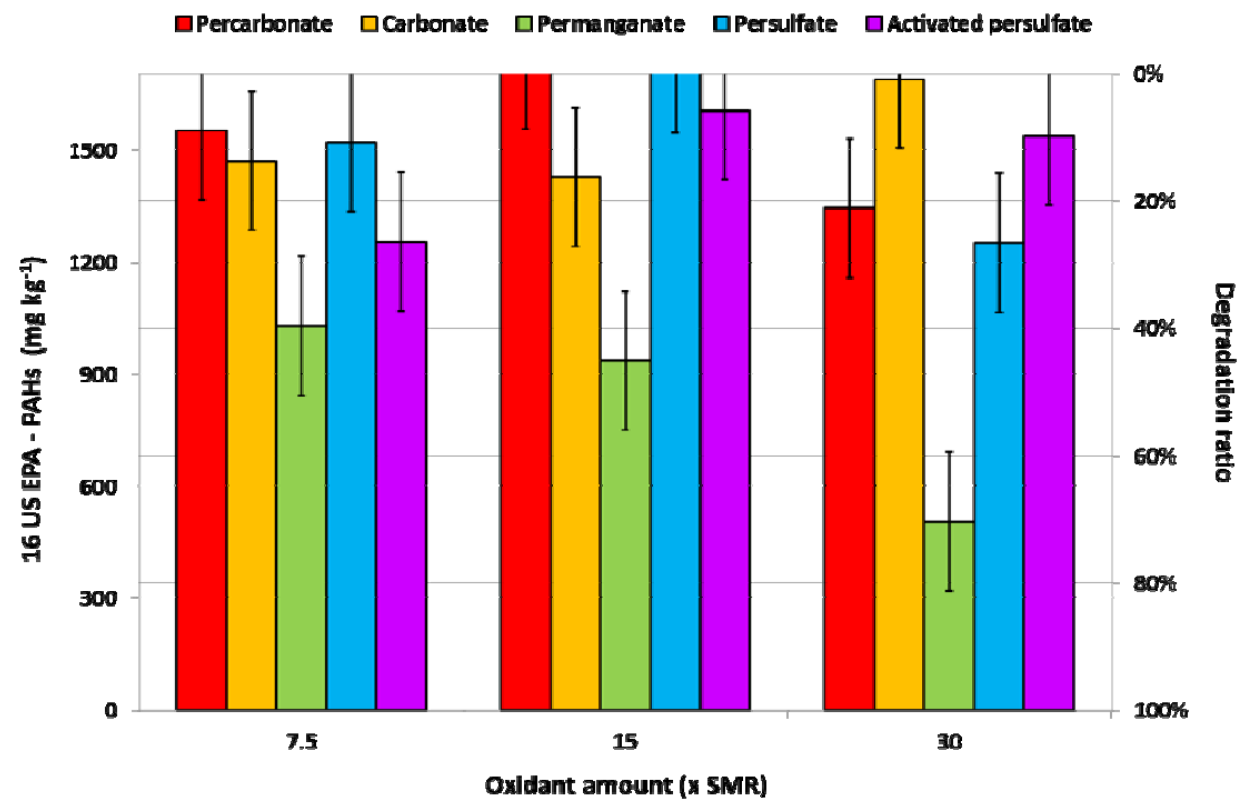

Fig. 1b 


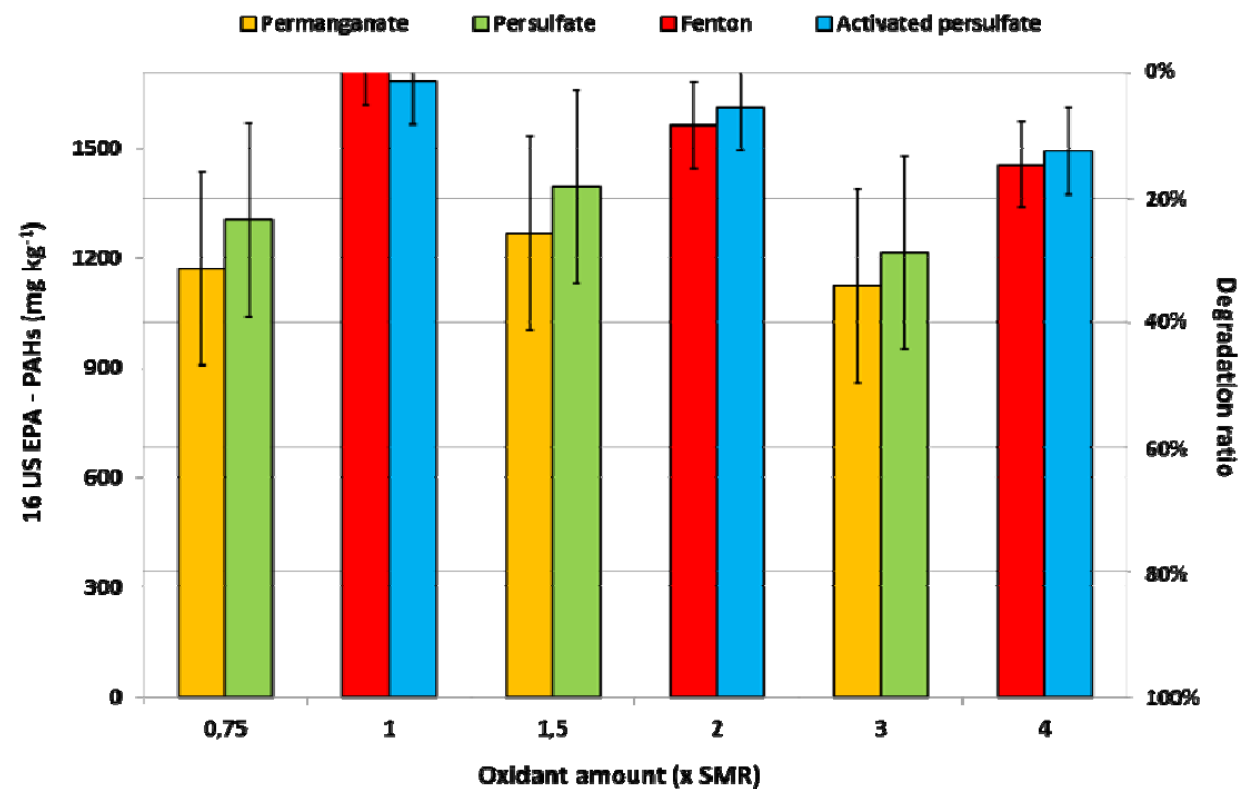

Fig. 2 


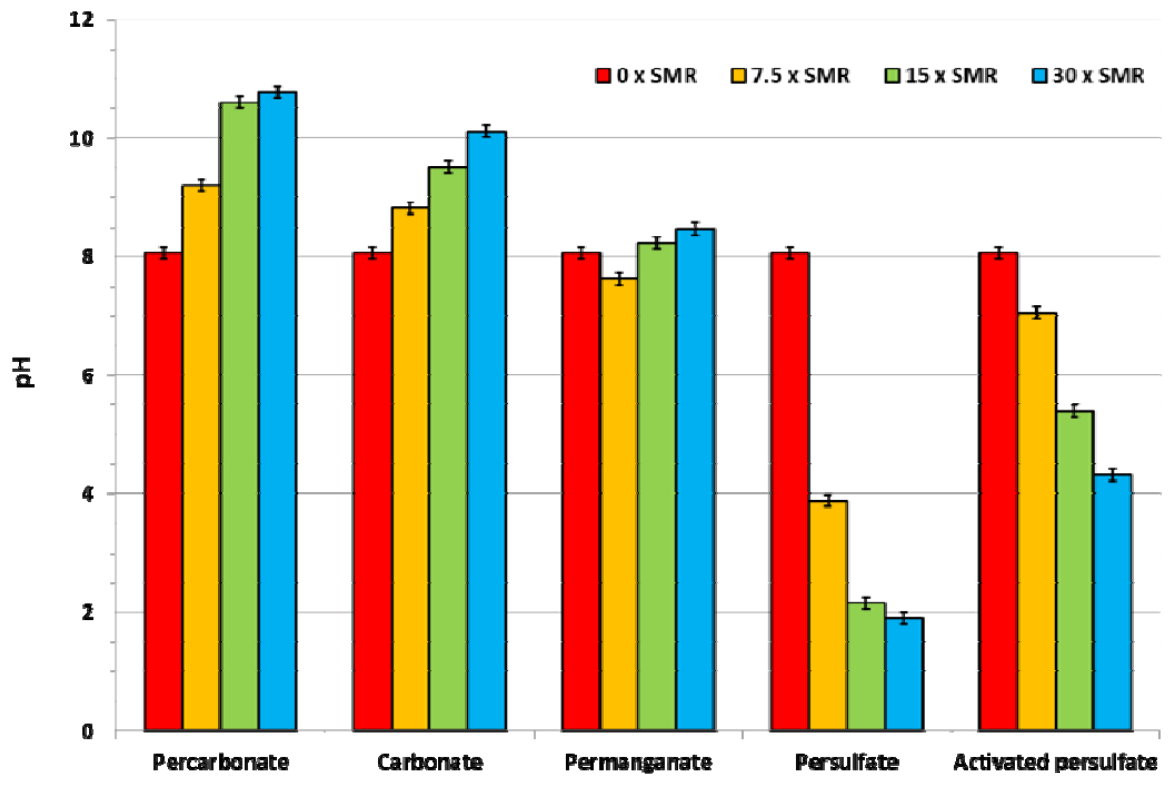

Fig. 3 


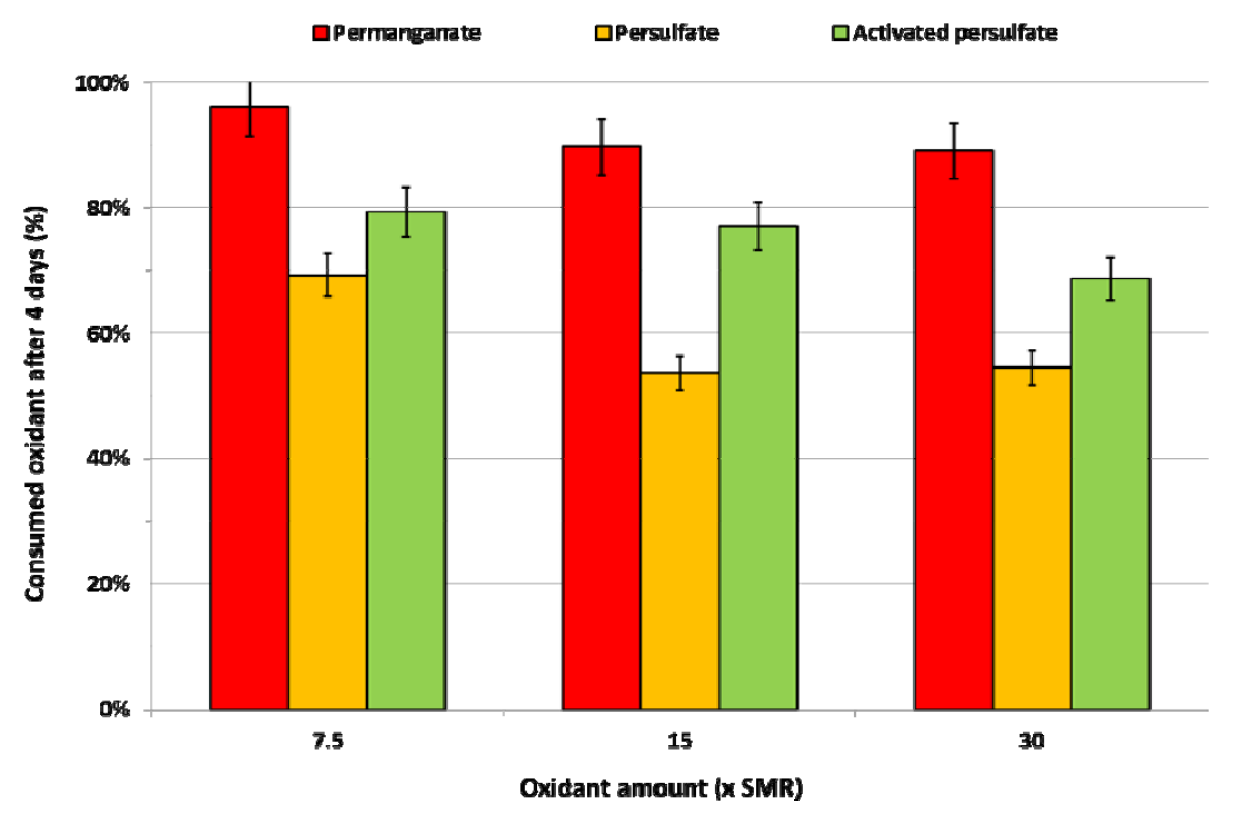

Fig. 4 


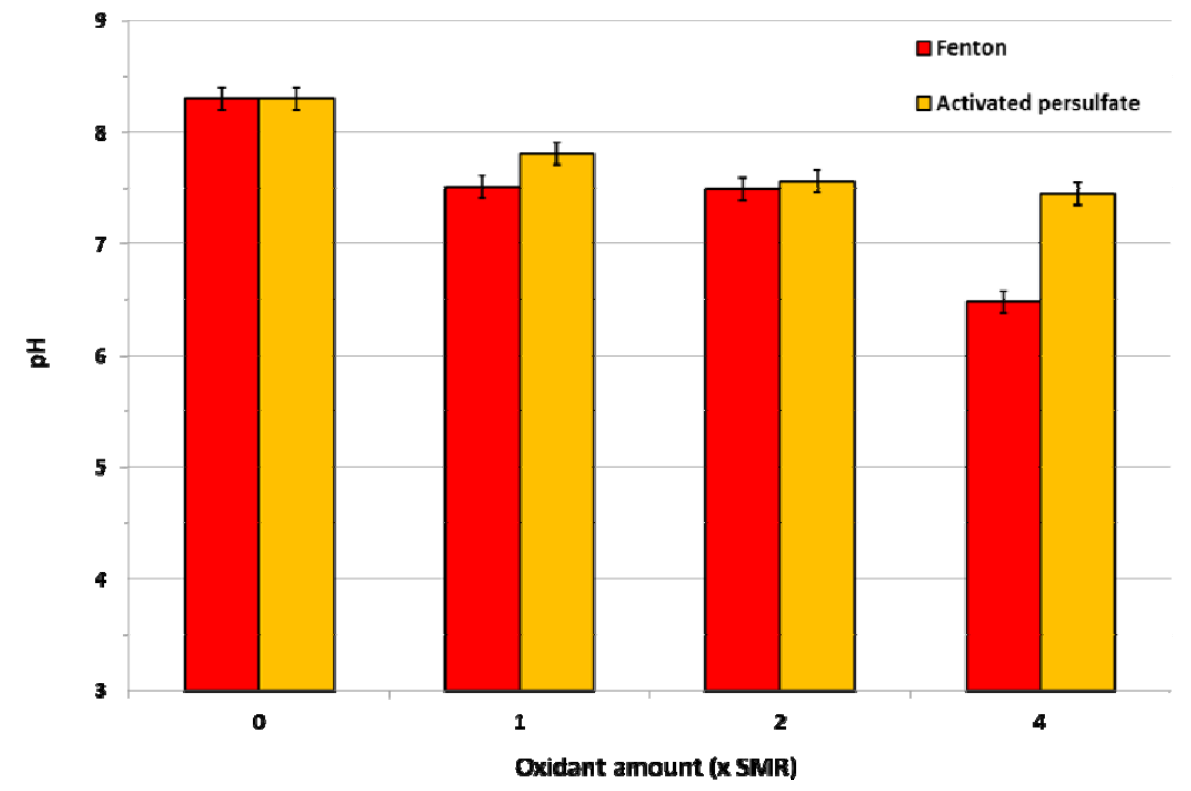

Fig. 5 
Table 1 Oxidant amounts (relatively to SMR) and number of oxidant additions used for all the experiments

\begin{tabular}{|c|c|c|c|c|c|c|c|c|c|c|c|}
\hline \multirow{2}{*}{$\begin{array}{l}\text { Oxidant } \\
\text { amount } \\
\text { (x SMR) }\end{array}$} & \multirow{2}{*}{$\begin{array}{l}\text { Number } \\
\text { of } \\
\text { additions }\end{array}$} & \multicolumn{4}{|c|}{ Fenton's reagent } & \multicolumn{2}{|c|}{ Activated persulfate } & \multirow{3}{*}{$\begin{array}{c}\text { Sodium } \\
\text { percarbonate } \\
\text { (g) }\end{array}$} & \multirow{2}{*}{$\begin{array}{l}\text { Sodium } \\
\text { carbonate } \\
\text { (g) }\end{array}$} & \multirow{2}{*}{$\begin{array}{l}\text { Sodium } \\
\text { persulfate } \\
\text { (g) }\end{array}$} & \multirow{2}{*}{$\begin{array}{c}\text { Potassium } \\
\text { permanganate } \\
\text { (g) }\end{array}$} \\
\hline & & $\begin{array}{l}\mathrm{H}_{2} \mathrm{O}_{2} 50 \% \\
\quad(\mathrm{~mL})\end{array}$ & $\begin{array}{c}\text { (g) } \\
\text { (facultative) } \\
\end{array}$ & $\begin{array}{c}\text { (g) } \\
\text { (facultative) } \\
\end{array}$ & $\begin{array}{l}\text { Cyclodextrin (g) } \\
\text { (facultative) }\end{array}$ & $\begin{array}{l}\mathrm{H}_{2} \mathrm{O}_{2} 50 \% \\
\quad(\mathrm{~mL})\end{array}$ & $\begin{array}{l}\mathrm{Na}_{2} \mathrm{~S}_{2} \mathrm{O}_{8} \\
\quad(\mathrm{~g})\end{array}$ & & & & \\
\hline \multicolumn{11}{|c|}{ High doses } & \\
\hline 7.5 & 1 & 1.09 & 0.55 & 0.21 & 1.24 & 0.91 & 0.75 & 1.99 & 1.34 & 4.52 & 2.00 \\
\hline 15 & 1 & 2.17 & 1.09 & 0.41 & 2.49 & 1.82 & 1.50 & 3.98 & 2.68 & 9.04 & 4.00 \\
\hline 30 & 1 & 4.35 & 2.17 & 0.82 & 4.98 & 3.64 & 3.00 & 7.96 & 5.36 & 18.08 & 8.00 \\
\hline \multicolumn{12}{|c|}{ Moderate doses } \\
\hline 0.75 & 1 & & & & & & & & & 0.45 & 0.20 \\
\hline 1.5 & 1 & & & & & & & & & 0.90 & 0.40 \\
\hline 3 & 1 & & & & & & & & & 1.81 & 0.80 \\
\hline 1 & 5 & 0.8 & 0.4 & - & - & 0.7 & 0.35 & & & & \\
\hline 2 & 10 & 1.6 & 0.8 & - & - & 1.4 & 0.7 & & & & \\
\hline 4 & 20 & 3.2 & 1.6 & - & - & 2.8 & 1.4 & & & & \\
\hline 8 & 40 & 6.4 & 3.2 & - & - & 5.6 & 2.8 & & & & \\
\hline 16 & 80 & 12.8 & 6.4 & - & - & 11.2 & 5.6 & & & & \\
\hline
\end{tabular}


Supplementary materials

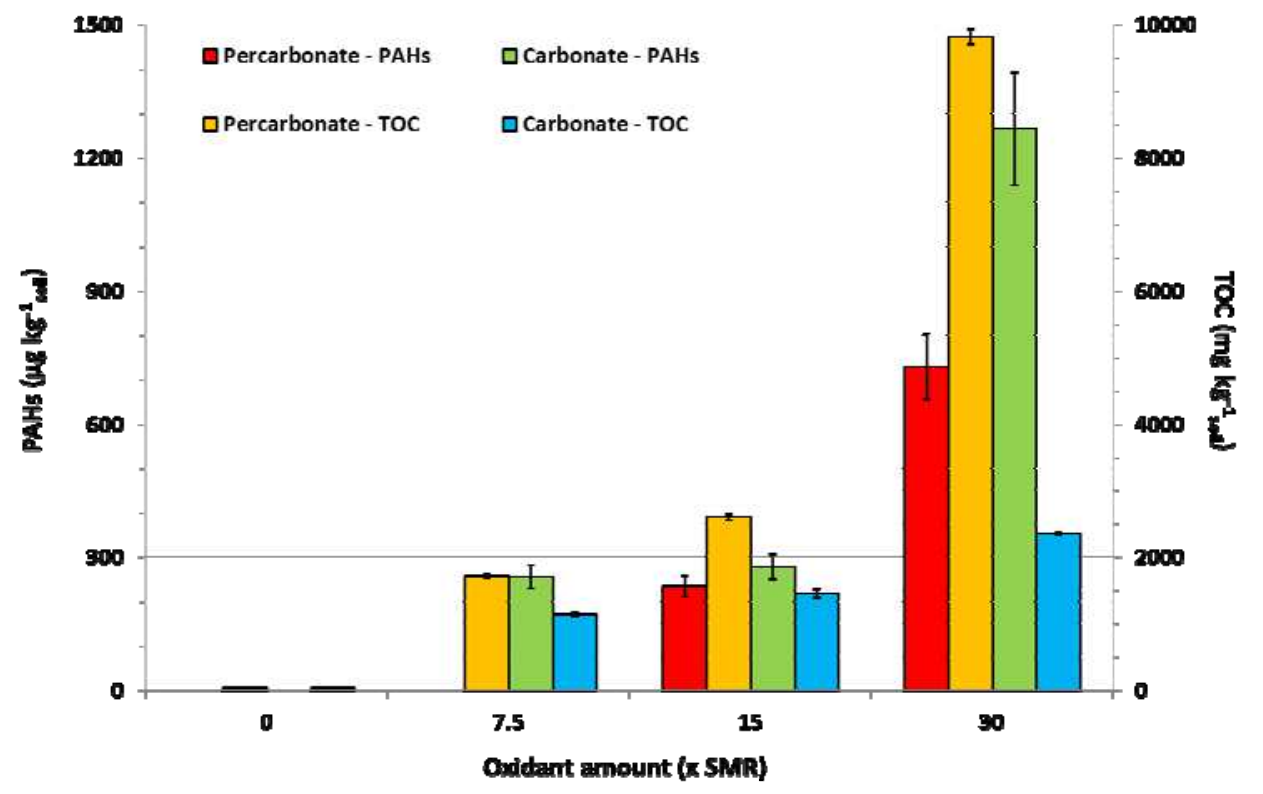

PAH and COT concentrations in the supernatant at the end of the reactions performed with high doses of percarbonate and carbonate. 